\title{
VISÕES DE ALTERIDADE E EXPERIÊNCIA DOCENTE
}

\author{
Rosângela Tenório de Carvalho ${ }^{1}$
}

\section{Resumo}

Este artigo tem como objeto o discurso sobre alteridade em articulação com experiência docente. Pretende-se dar visibilidade à expressão material, conceitual e pedagógica desse discurso em suas relações. A reflexão está sustentada nos estudos pós-colonialistas e pós-estruturalistas. Problematiza-se a interpretação da alteridade como uma possibilidade de acessar a experiência do outro, sentir como o outro em sua essencia, pois entende-se que não há uma natureza humana, mas, sim, humanos produzidos culturalmente e linguisticamente. O enfoque recai sobre a alteridade como uma relação de interdependência permeada por relações de poder, a versão da afirmação da diferença e a dignidade nas relações.

Palavras-chave: Alteridade; Diferença cultural; Docência.

\section{VISIONS OF OTHERNESS AND TEACHING EXPERIENCE}

\begin{abstract}
This article has as its object the discourse on otherness in articulation with teaching experience. It is intended to give visibility to the material, conceptual and pedagogical expression of this discourse in their relations. The reflection is sustained in postcolonialist and poststructuralist studies. The interpretation of otherness as a possibility to access the experience of the other is problematized, to feel as the other in its essence, because is understood that there is no human nature, but human beings produced culturally and linguistically. He focus is on otherness as a relation of interdependence permeated by power relations, the version of affirmation of difference and dignity in relationships.
\end{abstract}

Keywords: Otherness; Cultural difference; Teaching.

\footnotetext{
${ }^{1}$ Doutora em Ciências da Educação pela Universidade do Porto; Professora na Universidade Federal de Pernambuco/UFPE; E-mail: rosangelatc@gmail.com
} 


\section{Introdução}

O dilema da alteridade na educação pode ser visto como uma questão central na atualidade no Brasil e no mundo, haja vista a tensão nas relações em dimensões diversas e no discurso da humanização, um dos pilares do discurso iluminista, que pressupôs ao seu nascedouro uma relação civilizada entre os humanos. Lembremos com Kant em La Pedagogia o argumento do homem como única criatura a ser educada - disciplinado, instruído, civilizado e com discernimento sobre o que é bom (KANT, 1963, p. 6). Ou mesmo um dos mais significativos discursos pedagógicos do século XIX, na emergência da escola moderna, produzido pelo texto literário inicialmente chamado La Storia d' un burattino e em seguida nominado Pinóquio de Carlo Lorenzini Collodi, no qual a escola é tratada como o lugar da formação do sujeito de honra, o lugar do sujeito homem-educado.

Pinóquio trata de um inumano em busca da socialização nas práticas culturais da arte do circo, dos jogos e das brincadeiras ao sair de casa a flanar e se encantar com o mundo que encontra. Pinóquio, o personagem, precisa ser educado pela escolarização com seus rituais e artefatos para assim tornar-se homem. Para isso precisa abandonar a "graça do inumano" para tornar-se um sujeito humano (AGAMBEN, 2007, p.32).

O enunciado do sujeito humano educado desenhado a partir de um determinado modelo de humano - europeu branco, masculino, heterossexual, judaico-cristão - parece estar em ruínas desde as trágicas experiências das Guerras Mundiais, da Guerra do Vietnã e das guerras contínuas do século atual. O seu contraponto à inumanização reaparece nas reflexões sobre os campos de concentração, Auschwitz em particular, quando se trata de vidas que se enquadram na definição de vida indigna de ser vivida, de experiências terríveis, dolorosas, tal como foi tratada na filosofia em obras que tratam da condição humana (ARENDT, 1981; ELIAS, 1991).

Para além dessas questões, o discurso da supremacia da razão ocidental e a sua rejeição ao outro permeiam práticas sociais que são avolumadas quando associadas ao neoliberalismo econômico e sua chamada para a produção de um tipo de sujeito sob medida, agora um empreendedor competitivo. Essa é uma reflexão que emerge na literatura sociológica sobre o modo como o neoliberalismo impera. Contudo, sob a tensão das relações sociais e culturais, a singularidade e a pluralidade dos sujeitos estão a nos interpelar pela diferença. Há muito, os 
Outros deixaram de ser os povos primitivos, exóticos. Hoje os Outros são os sem-tetos, semterras, operários, camponeses, negros, gays, mulheres. Clamam pelo respeito à diferença, pela dignidade na forma de vida, pela inclusão, pelo direito de estar no mundo (CORAZZA, 2005). Outros que "lutam para que nunca mais sejam vistos como vítimas ou culpados, fontes de todo o mal, desvios a serem tolerados. Para que nunca mais suas diferenças sejam governadas, traduzidas, calibradas, reparadas, integradas ao velho princípio da identidade universal" (CORAZZA, 2005, p. 9).

As reações são múltiplas - acolhimento, rejeição, estranhamento, confronto, oportunismo; os usos, diversos - mercadológicos, sazonais, eleitoreiros; tolerados, respeitados. Tensão permanente nos espaços públicos e privados. Com efeito, na atualidade, os campos de refugiados, as meninas-bombas, os imigrantes nos espaços heterotópicos (FOUCAULT, 2001) os barcos vagantes em busca de um território - nos quais a vida nada vale e pode, tal como nos navios negreiros, ser absolutamente dispensável; os grupos humanos que morrem em crimes ambientais; os feminicídios e a homotransfobia - que coincidem em sua maioria com a própria condição de pessoas em sua raça; em sua condição de sexualidade; em sua condição de classe; em sua condição étnica, em sua condição de ter uma deficiência. Pela força, pelas relações assimétricas de poder.

Convive-se com um discurso de consciência da alteridade e dignidade humana e com formas sofisticadas de negação ou mesmo aniquilação do outro, abordadas pelo campo filosófico, como em Arendt (2009), ao tratar da banalidade do mal ou da ação política na qual se vê o mundo como plural, da responsabilidade vinculada a ele como condição educativa (formação) para o outro poder vir a ser efetivamente outro; ou por Agamben com suas reflexões sobre o homo sacer - produzido pela máquina antropológica, isto é, "por uma série de espelhos em que o homem, ao olhar-se, vê a própria imagem deformada", mas que o define como da espécie homo sapiens e assim dá-se o reconhecimento como humano (AGAMBEN, 2012, p. 44).

Há uma inquietação nas sociedades ocidentais com os movimentos de afirmação da diferença, seja pelo estranhamento ou medo, seja por razões políticas, por posições fascistas nas quais o consumismo de si mesmo é um dos pilares, mobilizando a aniquilação do outro. Questões que não estão fora do debate da desigualdade social, se entendemo-las para além do conhecimento instrumental, como defendeu Freire, ao anunciar em meados do século XX que 
"a compreensão crítica das chamadas minorias de sua cultura não se esgota nas questões de raça e de sexo, mas demanda também a compreensão nela do corte de classe” (FREIRE, 2005, p. 156).

Entendendo-se por alteridade o pressuposto da interdependência entre os indivíduos e que essa relação de interdependência não significa ter a experiência do outro, sentir como o outro, saber tudo sobre o outro; ou mesmo precisar saber tudo de si para compreender o outro, pois não há uma natureza humana, mas, sim, humanos produzidos culturalmente e linguisticamente, nessas relações de interdependência permeadas por relações de poder. Defendem-se, sim, a afirmação da diferença e a dignidade nas relações.

Para tratar do tema da alteridade na experiência docente, organiza-se este ensaio de forma que na primeira seção a expressão material do enunciado da alteridade no campo da educação -remete ao movimento desse enunciado em sua superfície de materialidade (FOUCAULT, 1995). Na sequência, trata-se a alteridade a partir da expressão epistemológica que remete à vontade de saber e de poder dizer do conhecimento sobre a alteridade e experiência docente - aqui um recorte da conceitualização sobre alteridade. E, por fim, para concluir, observa-se a expressão pedagógica, neste caso a ação discente e docente como uma experiência, um empreendimento de relação.

\section{Alteridade: o discurso em sua materialidade}

Como expressão material do discurso da alteridade e docência, destaco a proliferação de conteúdos identitários nas leis no campo educacional desde meados dos anos 1990, refletindo sobre o debate construído desde a redemocratização brasileira; uma produção imensa na indústria cultural trazida para o campo da docência, sendo essa produção de variadas orientações, dirigida a todos os níveis educacionais e uma prática cultural concreta de sujeitos da educação, cujo protagonismo político tem surpreendido de forma estimulante para alguns e preocupante para outros.

A legislação educacional incorpora de forma pertinente o debate da diversidade cultural, seja por meio da inclusão em suas diretrizes de formação de professores, seja em políticas de cotas. Educação do campo, Educação Quilombola, Educação Indígena, e ainda formações específicas para professores Indígenas e Quilombolas, inclusão de disciplinas como Libras nos 
diversos cursos superiores. Essa legislação, por sua vez, está tensionada com uma legislação conservadora, a exemplo do Estatuto da Família, que define família como a união entre homem e mulher; da retirada do discurso de gênero e sexualidade do Plano Nacional de Educação e de planos estaduais e municipais de educação. Mais recentemente houve, em relação à Base Curricular Comum Nacional para Educação Básica, a tentativa de implantação de lei punitiva para coibir ou proibir no currículo e na docência as temáticas de gênero e sexualidade, ideológicas, filosóficas, sociológicas e políticas - o discurso da Escola sem Partido.

A legislação como norma é uma ação em busca de hegemonia de um modo de ser professor/a, como está posto na Base Nacional Comum Curricular, no seu Capítulo V, Artigo 17. Na perspectiva de valorização do professor e da sua formação inicial e continuada, as normas, os currículos dos cursos e programas a eles destinados devem adequar-se à BNCC, nos termos do $\$ 8^{\circ}$ do Artigo 61 da LDB, devendo ser implementados no prazo de dois anos, contados da publicação da BNCC, de acordo com Artigo 11 da Lei n ${ }^{\circ}$ 13.415/2017. Vale dizer, contudo, que os limites da legislação de regulação da sociedade para a produção dos sujeitos sociais na busca de capturar os sujeitos da educação idealmente não são verticais e inexoráveis, se entendermos que as regras que governam essas legislações são mais amplas em conteúdo e capilaridade e que através dessas legislações são corporificadas. Com isso, quero dizer que há uma luta cultural e social pelo dizer, que a legislação não tem a condição material de anular. E essa luta é uma luta política.

No campo da indústria cultural, em sua interpenetração com o campo educacional, vale ressaltar que estamos em um cenário de produção de uma grande interlocução entre grupos humanos, comunidades na internet e ao mesmo tempo colocando-nos diante do que se reconhece como "governo da cultura". Da produção da indústria cultural em relação ao tema da alteridade destaco o cinema com os seus clássicos Hiroshima, meu amor, de Alain Resnais (1959); Chocolate, de Lasse Hallström (2001); Dom Juan DeMarco, de Jeremy Leven (1995); Nenhum a menos, de Zhang Yimou (1999); e tantos filmes que levamos para a escola, para a universidade em nossa atuação docente. Eles falam da alteridade. Ao seu modo, é claro.

$\mathrm{O}$ cinema e a educação têm feito alianças no âmbito da docência pela capacidade de cada um desses campos de afetar o outro. Há aqueles que defendem, dentre os quais me incluo, que essa aliança não deve ser feita para se apresentar o cinema como ilustração, o que seria sua mera repetição, mas porque o cinema pode conduzir a educação a novos lugares, a pensar o 
diferente, pode afetar produzindo um estado de ruído, de estranhamento na função comunicativa da educação de modo a levá-la a novos devires, à emergência de um novo tempo (DINIS, 2005). Aqui o próprio cinema como um campo outro.

Hiroshima, meu amor complica ainda mais a situação. [...] E quando o japonês recusa que a mulher entre em sua própria região ("Vi tudo...tudo - você nada viu em Hiroshima, nada...”), a mulher atrai o japonês para a sua, até certo ponto, voluntário e consentidor. Não seria para cada um uma maneira de esquecer sua própria memória, e de constituir uma memória a dois, como se agora a memória se tornasse mundo e se destacasse deles? (DELEUZE, 1990, p. 144, apud DINIS, 2005, p. 76).

As temáticas autobiografia, diferença cultural, vida de imigrantes em outros países compõem um outro campo da literatura com o tema da alteridade - a novela gráfica - gibi para adultos. Dentre os trabalhos autobiográficos, alguns exemplos: Retalhos narra a história da infância e da adolescência de Craig Thompson; o brilhante texto A Chegada de Shaun Tan trata sobre imigrantes; o texto Azul é a Cor Mais Quente de Julie Maroh aborda com sensibilidade o amor entre duas jovens; a novela gráfica Cumbe de Marcelo D’Salete que trata da experiência da escravidão no Brasil. Um destaque para novela gráfica Fagin, o Judeu, na qual o autor Will Eisner relembra tempos como o da Segunda Guerra Mundial, o "pérfido preconceito que permeava meu mundo" o uso do estereótipo. Nos tempos recentes, temos o mesmo preconceito em três manifestações diferentes: "contra aqueles que não são brancos, ele se revela no racismo; contra os pertencentes a outras etnias, sua manifestação é o nacionalismo; contra os judeus, assume a forma do antissemitismo" (EISNER, 2005, p. 9).

Para Silva (1999), o estereótipo pode ser visto como uma forma de representação. O estereótipo opera de forma que o outro é visto "por meio de uma forma especial de condensação, em que entram processos de simplificação, de generalização, de homogeneização" (SILVA, 1999, p. 51). Funciona de forma ambígua, já que envolve ao mesmo tempo uma vontade de conhecer e ao mesmo tempo um impulso de afastamento do outro. Como bem observa Silva (1999), a ação de estereotipar não é uma disjunção entre o real e uma imagem, ou seja, não é uma forma distorcida do real, por isso que o estereótipo não é facilmente desmontável. A ambiguidade do estereótipo está bem desenhada no clássico Pele Negra, Máscaras Brancas, de Fanon (1975), ao abordar a representação da mulher branca em relação ao homem negro na França nos anos 1950, quando enxerga uma potência a ser conhecida e o impulso de afastamento, o medo. Essas 
representações produzem significados, que não são falsos nem verdadeiros; esses significados “são funções de posições específicas de poder e promovem posições de poder", tal como aprendemos com Silva (1999, p. 24).

Um outro aspecto importante que aparece no texto autobiográfico de Eisner trata de uma outra forma de produção de estereótipos, agora na linguagem imagética. $\mathrm{O}$ autor identificou e nomeou de difamação visual na literatura clássica formas de representação visual que agregam um tipo fixado de fisionomia de judeu como forma de subalternização. Questão ampliada nos estudos de Sales Júnior (2006), ao indicar como a piada, o chiste e os apelidos funcionam como microtécnicas de poder atuando no discurso racista.

Na literatura brasileira, outro campo de alianças com a educação e com a prática docente, destacamos dois textos: Quarto de despejo: diário de uma favelada, de Carolina Maria de Jesus; e Esses poetas: uma antologia dos anos 90, de Heloisa Buarque de Hollanda. O primeiro, de 1960, é um relato autobiográfico em diário de uma mulher negra sobre sua vida na favela; o segundo, uma publicação dos anos 1990, também trata da vida na favela e também realça a presença feminina na cena literária, e mais ainda a poesia negra, a poesia judaica, a presença outing gay na poesia 90 . No mesmo período, outros movimentos editoriais retratam o movimento editorial em favelas e comunidades residenciais mais pobres a exemplo da Antologia de Poetas da Baixada Fluminense, organizado por Cristina Siqueira pela Rio-Arte em 1987 dentre outros. Parte dessa produção reflete a inserção de mulheres negras, poetas vinculados ao MST, ou poetas vinculados a comunidades populares, a exemplo do Mangue Beat em Pernambuco. Vale destacar o trabalho extraordinário de Heloisa Buarque de Hollanda sobre Estéticas das periferias, no qual a pesquisadora tem ampliado a publicação literária de outsiders.

No Brasil, o desafio do racismo na literatura vem sendo tratado em obras nas quais o cânone da literatura é questionado pelas formas de visibilidade imagético-discursivas. Estudos em diferentes campos das Ciências Humanas expõem essa questões que não são consensuadas no que deve ser retirado ou não do mercado editorial.

Importa, nesse sentido, que possamos trazer a literatura como elemento de "tradução", metáfora da ação docente, aqui também inspirada por Lévi-Strauss quando diz que significar é a possibilidade de qualquer linguagem ser traduzida para uma linguagem diferente - na docência o ato de traduzir está implicado com a possibilidade de significar e fazer significar, não de uma 
forma, mas de várias formas. Traduzir o que é estranho para nós, buscar uma aproximação, roçar as fronteiras que separam os diferentes.

\section{Alteridade: elementos epistemológicos do enunciado}

Utilizando o modo como Gallo (2008) trata os conceitos - criados a partir de problemas, com uma história; um entrecruzamento; uma heterogênese; uma ordenação de seus componentes por região de vizinhança; incorporais, embora estejam encarnados nos corpos, mas não são a coisa em si mesma e, ao mesmo tempo, são absolutos e relativos -, vamos tratar do conceito de alteridade, a partir de diferentes formas de interpretação.

A alteridade é tema tratado, na filosofia, na psicologia, na antropologia, na educação, no cinema, na literatura, na música, no teatro e em outros campos, como um desejo de homens e mulheres responderem às inquietações sobre si e sobre os outros. Pode ser entendida como o Ser outro; como o constituir-se como outro; colocar-se no lugar do outro. Pode ser entendida como a ação de ser, de apreender o outro na plenitude da sua dignidade, dos seus direitos e, sobretudo, da sua diferença. Segundo Abbagnano (2007), a alteridade é um conceito mais restrito do que diversidade e mais extenso do que diferença. A diversidade é um contraponto à identidade. A diferença é a determinação da alteridade, está assim implicada com relações interhumanas. Nessas relações "Se me conheço, conheço ao outro. Sair de si para o Outro, como defendeu Sartre, ou o reconhecimento do Outro como infinitivamente Outro de Levinas em sua defesa ética da defesa da experiência com o Outro. (ABBAGNANO, 2007, p. 37).

Sartre, em seu texto clássico Entre Quatro Paredes, ao tratar da relação entre o sujeito e o outro no diálogo entre os personagens, demonstra que as relações de alteridade têm ali um ponto de referência, dado na perspectiva do inferno: o inferno são os outros passa a ser um clichê, embora neste artigo se escolha trazer um pouco do enunciado na cena:

[...] Pois bem, é agora! O bronze aí está, eu o contemplo e compreendo que estou no inferno. Digo a vocês que tudo estava previsto. Eles previram que eu haveria de parar em frente deste bronze, tocando-o com minhas mãos, com todos esses olhares sobre mim. Todos esses olhares que me comem! (Volta-se bruscamente). Ah, vocês são só duas? Pensei que fossem muitas, muitas mais! (Ri). Então, é isso que é o inferno! Nunca imaginei... Não se lembram? O enxofre, a fogueira, a grelha... Que brincadeira! Nada de grelha. O inferno... O inferno são os outros! (SARTRE, 1977, p. 22). 
$\mathrm{Na}$ interpretação de Sartre, a consciência de cada um se constrói na relação no olhar externo, no contato com o mundo e com o que descobriu do outro. Em síntese, nessa perspectiva, é preciso sair de si para conhecer o outro. (GALLO, 2008). Sair de si para perceber o Outro, tal como aparece no texto literário de Saramago O Conto da Ilha Desconhecida:

Podíamos ficar a viver aqui, eu oferecia-me para lavar os barcos que vêm à doca, e tu, E eu, Tens com certeza um mester, um ofício, uma profissão, como agora se diz, Tenho, tive, terei se for preciso, mas quero encontrar a ilha desconhecida, quero saber quem sou eu quando nela estiver, Não o sabes, Se não sais de ti, não chegas a saber quem és. (SARAMAGO, 1998, p. 40, grifo nosso).

Simone de Beauvoir, em seu texto Segundo Sexo I, afirma que essa é uma categoria fundamental do pensamento humano. Para ela, "Nenhuma coletividade se define nunca como Uma sem colocar imediatamente a Outra diante de si". Ressalta que "bastam três viajantes reunidos por acaso num mesmo compartimento para que todos os demais viajantes se tornem 'os outros' vagamente hostis". Ou exemplifica que "para os habitantes de uma aldeia, todas as pessoas que não pertencem ao mesmo lugarejo são 'outros' e 'suspeitos"”; e também que, “para os habitantes de um país, os habitantes de outro país são considerados 'estrangeiros"”. E, ainda que “os judeus são 'outros' para o antissemita, os negros para os racistas norte-americanos, os indígenas para os colonos, os proletários para as classes dos proprietários” (BEAVOUIR, 1970a, p. 11).

Fanon (1975) em Pele Negra, Máscaras Brancas, assim como Beauvoir, faz um deslocamento da visão de Sartre para converter a alteridade em um modelo analítico da experiência colonial. Nesse sentido, vale trazer suas reflexões para tratar da relação entre o negro e o Outro branco. Do texto de Fanon um recorte chama a atenção para esse posicionar-se como o outro:

Os médicos das salas de consulta sabem-no. Vinte doentes europeus sucedem-se: "Sentese, senhor... O que o trouxe?... De que se queixa?..." - Chega um preto ou um Árabe: Senta-se, meu valente... Que é que tens?... Onde te doi?..." - Quando não é: "Que tu ter?..."

Falar "língua de preto" a um preto é vexá-lo, porque ele é aquele-que-fala-língua-de-preto.

[...] Falar "língua de preto" é exprimir esta ideia: "Mantém-te no teu lugar" (FANON, 1975, p. 47).

Retomamos Beauvoir, que, no livro o Segundo Sexo, volume II, adota a categoria existencial do outro - “as mulheres existem como outro". Beauvoir trata a alteridade também 
como maldita. Maldita, porque se inscreve na pele quando lhes é negado ser. Exemplifica com os negros da América do Norte, parcialmente integrados numa civilização que os considera, entretanto, como casta inferior: "Big Thomas sente com tamanho rancor na aurora de sua vida essa definitiva inferioridade, essa alteridade maldita que se inscreve na cor da pele: ele olha os aviões passar e sabe que por ser negro o céu lhe é vedado" (BEAVOUIR, 1970b, p. 39).

No caso específico do gênero, importa dizer que o discurso da igualdade de gênero vem sendo tensionado pelo debate sobre igualdade e diferença; o desafio da identidade; a contingência histórica da igualdade; a correlação entre identidades de grupo e a percepção plena da individualidade; e ainda o fato de os termos da exclusão sobre os quais a discriminação está amparada serem, ao mesmo tempo, negados e reproduzidos nas demandas por inclusão (SCOTT, 2005).

A visão da alteridade como diferença está por sua vez associada a "filosofias da diferença", para se referir a certas tendências filosóficas contemporâneas que se centram no conceito de diferença. Em consequência da chamada "virada linguística", no campo filosófico, entende-se que é precisamente a consciência que é deslocada — no caso dos pós-estruturalistas, pela linguagem, pelo texto e pelo discurso; no caso de Habermas, pela interação e pela intersubjetividade — como centro privilegiado do sentido e da ação.

Nas perspectivas teóricas pós-estruturalistas, a diferença passa a ser o foco principal tratado como um processo social estreitamente vinculado à cultura como prática de significação. Silva (1999, p. 65) afirma que "a diferença é experimental, é da ordem da proliferação, é um devir-outro, está próxima do que se entende por movimento e é percebida não na relação de diferença entre x e y, mas sim com o que se passa entre x e y".

De certa forma, estaríamos falando do que Stephen Stoer e António Magalhães (2003) nomearam de rebelião das diferenças, em referência a grupos e indivíduos que durante muito tempo estiveram subordinados às formas de subjetivação fundadas no Estado-nação e que passam a assumir-se como alteridade, configurando um processo de resistência às formas consolidadas por esse Estado. Em nosso olhar, os diferentes movimentos sociais têm representado bem essa rebelião das diferenças, o que está em consonância com os estudos póscoloniais de Bhabha (2001) no que dizem respeito ao híbrido, aquele que carrega em si as marcas do poder e também as marcas de resistência. Para Bhabha (2001, p. 5), a diferença cultural é um processo bastante complexo de significação através do qual se produzem 
afirmações a respeito da cultura que constituem e engendram diferenças, discriminações, ao mesmo tempo em que estão na base da articulação de relações de poder e de práticas sociais muito concretas de institucionalização, de dominação e de resistência.

Em Foucault a alteridade, tal como defende Ortega (1999. p. 124), se revela em três planos no pensamento foucaultiano: no próprio indivíduo, que através do trabalho sobre si se transforma; na prática social do cuidado, onde a transformação de cada um é compartilhada com os outros, seja como aprendizagem, ou simplesmente na abertura ao outro na forma de amizade; e na transformação do mundo. O cuidado, portanto, é um exercício que expõe o si à prova da obra, obra de si, obra do mundo e de sua transformação.

Suely Rolnik (1994 apud DINIS, 2005, p. 160), apoiada em Deleuze, afirma que o outro é tudo aquilo que é exterior a um eu. Contudo o Outro não é apenas um outro eu (o estrangeiro, a mulher, o negro, o homossexual, a criança...) com o qual devo criar um exercício de vizinhança baseado na filosofia do politicamente correto. O Outro é tudo aquilo (humano, não humano, visível, não visível) que me arranca da pretensa estabilidade de uma identidade fixa (um modo padronizado de pensar, sentir, agir), provocando-me com um incessante convite para diferentes formas de ser-estar no mundo.

Destaco também a posição de Irigaray (2004) ao defender a necessidade de tratar o outro como substantivo. Nesse sentido não é o outro neutro, nem gramaticalmente, nem semanticamente, pois não é mais possível utilizar indiferentemente a mesma palavra para o masculino e o feminino. Nessa perspectiva a alteridade do outro se expressa na estranheza de seu comportamento, na resistência, na busca da horizontalidade, "da partilha de vida que respeita absolutamente o outro como outro, além de todas as intuições, sensações experiências, conhecimentos que pode ter”, diz Irigaray (2002, p. 11).

\section{Alteridade no discurso educacional}

Para além da materialidade e da conceitualização aqui brevemente apresentadas, há que se destacar na experiência visível no convívio dos estudantes e das estudantes em escolas e universidade o estranhamento de professoras/es com a presença gay, travesti; o uso de livros de ocorrências com linguagem policial para o relacionamento com os pais ou conselho tutelar; os conflitos religiosos; a presença de pessoas negras de forma organizada em grupos; as rebeliões 
dos estudantes; os protestos; as ocupações; as escolhas estéticas. Os modos de ser e estar no mundo interpelam-nos pela diferença o tempo inteiro.

Freire (1997), com um discurso identificado com o conceito de alteridade para além da identidade, insere no conceito de diálogo o questionamento relativo a visões reacionárias do Outro: "como posso dialogar, se me sinto participante de um ' $g$ hetto' de homens puros, donos da verdade e do saber, para quem todos os que estão fora são 'essa gente', ou são 'nativos inferiores'?" (FREIRE, 1997, p. 115). Desde Freire, no plano pedagógico, o discurso pela interculturalidade, anunciado pelas racionalidades sociopolíticas e epistemológicas, sustenta a prescrição dialógica entre culturas e a constituição do cidadão multicultural, ou seja, sustenta uma pedagogia que tem como preocupação a produção de identidades culturais que contemplem as alteridades multidimensionais a partir do gênero, raça, geração, sexualidade, classe.

Retomamos a Hannah Arendt para trazer a possibilidade de se pensar a escola como esfera pública:

como mundo comum, reúne-nos na companhia uns dos outros e, contudo evita que colidamos uns com os outros, por assim dizer. O que torna tão difícil suportar a sociedade de massas não é o número de pessoas que ela abrange, ou pelo menos não é este o fator fundamental; antes, é o fato de que o mundo entre elas perdeu a força de mantê-las juntas, de relacioná-las umas às outras e de separá-las. (ARENDT, 1981, p. 62).

Nos anos recentes, as questões da diferença cultural permeiam o cotidiano das escolas, inclusive com a experiência de afirmação cultural. Um acontecimento que merece ser ressaltado: vai ter shortinho, sim!, ação divulgada nas mídias sociais e que repercutiu no país. O fato ocorreu no Colégio Anchieta de Porto Alegre. Um grupo de estudantes de 13 a 17 anos contesta as regras do vestuário do colégio e faz um abaixo-assinado nomeado Vai ter shortinho, sim!. Alguns trechos do abaixo-assinado dão o que pensar sobre o tema que estamos trabalhando: 
homens a não sexualizar partes normais do corpo feminino. Nós somos adolescentes de 13-17 anos de idade. Se você está sexualizando o nosso corpo, você é o problema. (FRAGA, 2016).

Como a docência considera essa ação e a própria produção cultural que tem visibilidade hoje no uso de celulares para acessar o Facebook, o Twitter, ou WhatsApp com o impacto performático refletindo-se no modo de ser e estar no mundo das pessoas? Como professores/as veem na questão da alteridade um elemento constitutivo da docência? Entende-se a docência como uma relação de alteridade, pois o/a professor/a e o/a estudante são o Outro que exerce atos de interpelação recíproca, propondo uma relação de diferenças e não de submissão a imagens que possam ser atribuídas um ao outro como uma autodefesa. Evidente que não se perde de vista que essa relação é uma relação de poder, na qual os/as professores/as em nossas institucionalidades exercem muitas vezes uma relação de verticalidade.

Interessa seguir uma docência que amplie o mesmo sentido do planejamento, do currículo e da didática, não pela repetição, mas pela condução a outros lugares para fazer pensar diferente pela experiência com a diferença. Trata-se de perceber a alteridade que tem o Outro como diferença e a docência como uma experiência de tradução. Sobre a experiência, acolho o modo como Larrosa a trata: como um princípio de alteridade. Em suas palavras:

A experiência é "isso que me passa". [...] A experiência supõe, em primeiro lugar, um
acontecimento ou, dito de outro modo, o passar de algo que não sou eu. E "algo que não
sou eu" significa também algo que não depende de mim, que não é uma projeção de mim
mesmo, que não é resultado de minhas palavras, nem de minhas ideias, nem de minhas
representações, nem de meus sentimentos, nem de meus projetos, nem de minhas
intenções, que não depende nem do meu saber, nem de meu poder, nem de minha
vontade. "Que não sou eu" significa que é "outra coisa que eu", outra coisa do que
aquilo que eu digo, do que aquilo que eu sei, do que aquilo que eu sinto, do que aquilo
que eu penso, do que eu antecipo, do que eu posso, do que eu quero. Chamaremos a isso
de "princípio de alteridade". Ou, também, de "princípio de exterioridade". Ou, ainda, de
"princípio de alienação". (LARROSA, 2011, p. 5).

Para o autor, a possibilidade da experiência supõe a suspensão de uma série de vontades: a vontade de identificar, a vontade de representar, a vontade de compreender. A possibilidade da experiência supõe, em suma, que o real se mantenha em sua alteridade constitutiva (LARROSA, 2011, p.18).

Admitir a diferença, esse é o desafio - lidar com a diferença que está posta, lidar com o que não somos, lidar com o que estranhamos, não para ocidentalizar o mundo, não para universalizar, não para se comparar a um universal, não para apagar identidades. Admitir a 
diferença sem subalternizar. Não há um ponto de chegada, mas um desejar ser docente para a alteridade.

Essa perspectiva, aliada a uma ideia de docência como tradução (CORAZZA, 2016), potencializa uma experiência outra com o conhecimento, seja ele filosófico, científico, artístico. Não o mesmo, não uma cópia, ou uma dublagem, mas o cultivo de uma prática da tradução, que, mesmo mantendo uma equivalência de código ou de sentido, revitaliza pela tradução. Movimentar-se pela arte de formar, inventar, estabelecer uma relação de alteridade.

Tratar da docência remete ao papel da universidade como formadora, o que significa pensar na existência de expressivo movimento de valorização de discursos em defesa das identidades culturais, ao tempo em que se acolhem a alteridade e os processos de diálogo entre culturas. É possível afirmar-se que assistimos nos últimos 30 anos a uma proliferação de discursos contrários à epistemologia monoculturalista, versão que “cultura" uma visão essencialista sobre a identidade dos sujeitos coletivos, e que está sedimentada nos valores universais do projeto de civilização ocidental, branco, cristão, heterossexual.

Concordamos com Umberto Eco que, ao tratar da primeira universidade, a de Bolonha de 1088, defende ser um lugar que pode significar uma comunidade cultural. Para ele, a universidades: "Nos últimos novecentos anos, elas têm sido a matriz de uma identidade internacional e artífices dos capítulos mais criativos na história da cultura ocidental". Lembra Eco que "Não raramente, grupos de acadêmicos deram apoio ao colonialismo, ao racismo e à intolerância". Contudo para ele "Isto não elimina que é precisamente no leito das universidades ocidentais e das academias que o mundo moderno concebeu um novo modo de abordar as culturas e as civilizações, que recebeu o nome de antropologia cultural (ECO, 2013, p. 3-4).

Eco (2003, p. 3) fala também, a respeito do sentido das universidades no contexto do "tumulto do mundo atual", que são "os únicos locais de silêncio, ao lado das sedes de meditação religiosa". Para ele, as universidades "ainda fazem parte daqueles poucos lugares em que é possível um confronto racional entre diversas visões do mundo", o que pode ser interpretado como uma defesa da universidade da diferença. 


\section{Referências}

ABBAGNANO, Nicola. Dicionário de Filosofia. São Paulo: Martins Fontes, 2007.

AGAMBEN, Giorgio. Profanações. São Paulo: Boitempo, 2007.

AGAMBEN, Giorgio. O aberto: o homem e o animal. Lisboa: Edições 70, 2012.

ARENDT, Hanna. A Condição Humana. Rio de Janeiro: Forense Universitária; São Paulo: Salamandra/Edusp, 1981.

ARENDT, Hanna. Eichmann em Jesusalém. São Paulo: Companhia das Letras, 2009.

BHABHA, Homi. O Local da Cultura. Belo Horizonte: Autêntica, 2001.

BEAUVOIR, Simone de. O Segundo Sexo: Fatos e Mitos. São Paulo: Difusão Européia do Livro, 1970a. v. 1.

BEAUVOIR, Simone de. O Segundo Sexo. Rio de Janeiro, Nova Fronteira, 1970b. v. 2.

BRASIL. Lei n ${ }^{\circ}$ 9.394, de 20 de dezembro de 1996. Estabelece as diretrizes e bases da educação nacional. Brasília, DF, Diário Oficial da União, 23 dez. 1996.

BRASIL. Lei $\mathrm{n}^{\circ} 13.415$, de 16 de fevereiro de 2017. Altera as Leis $\mathrm{n}^{\circ}$ 9.394, de 20 de dezembro de 1996, que estabelece as diretrizes e bases da educação nacional, e 11.494, de 20 de junho 2007, que regulamenta o Fundo de Manutenção e Desenvolvimento da Educação Básica e de Valorização dos Profissionais da Educação [...]. Brasília, DF, Diário Oficial da União, 17 fev. 2017.

COLLODI, Carlo. Pinocchio: Primi Grandi Libri. Firenze: Casa Editrice Salani, 1956.

CORAZZA, Sandra Mara. Nos tempos da educação: cenas de uma vida de professora. Revista da ABEM, Porto Alegre, v. 12, p. 7-10 mar. 2005.

CORAZZA, Sandra Mara. Currículo e Didática da Tradução: vontade, criação e crítica. Educação \& Realidade, Porto Alegre, v. 41, n. 4, p. 1313-1335, out./dez. 2016.

DINIS, Nilson Fernandes. Educação, cinema e alteridade. Educar, Curitiba, n. 26, p. 67-79, 2005.

D'SALETE, Marcelo. Cumbe. São Paulo: Veneta, 2018.

ECO, Umberto. Por que as universidades? Tradução de Marco A. Nogueira. Bologna, 2013. Disponível 
https://edisciplinas.usp.br/pluginfile.php/656188/mod_folder/content/0/Extras/Por\%20que\%20as $\%$ 20universidades.pdf?forcedownload $=1$.

EISNER, Will. Fagin, o judeu. São Paulo: Companhia das Letras, 2005.

ELIAS, Norbert. Condição Humana. Memória e Sociedade. Lisboa: Difel, 1991.

FANON, Frantz. Pele Negra, Máscaras Brancas. Porto: Paisagem, 1975.

FRAGA, Rafaela. Alunas fazem mobilização pelo uso de shorts em escola de Porto Alegre. Portal G1 RS. Publicado em 25 fev. 2016. Disponível em: http://g1.globo.com/rs/rio-grande-dosul/noticia/2016/02/alunas-fazem-mobilizacao-pelo-uso-do-shorts-em-escola-de-portoalegre.html.

FOUCAULT, Michel. A Arqueologia do Saber. Rio de Janeiro: Forense Universitária, 1995.

FOUCAULT, Michel. Outros Espaços. In: MOTTA, M. B. da (Org.). MichelFoucault: Estética: Literatura e pintura, música e cinema. Rio de Janeiro e São Paulo: Forense Universitária, 2001.

FREIRE, Paulo. Pedagogia do Oprimido. 42 ed. Rio de Janeiro: Paz e Terra, 2005.

FREIRE, Paulo. Pedagogia da Esperança: um reencontro com a Pedagogia do Oprimido. Rio de Janeiro: Paz e Terra, 1997.

GALLO, S. Eu, o outro e tantos outros: educação, alteridade e filosofia da diferença. In: Congresso Internacional Cotidiano: Diálogos Sobre Diálogos, 2., 2008, Niterói. Anais. Rio de Janeiro: Universidade Federal Fluminense, 2008.

HOLLANDA, Heloisa Buarque de. Esses poetas: uma antologia dos anos 90. São Paulo: Aeroplano, 1998.

IRIGARAY, Luce. A questão do outro. Tradução Tania Navarro Swain. Labrys, Estudos Feministas, $\quad$ n. 1-2, jul./dez. 2002. Disponível em: http://historiacultural.mpbnet.com.br/feminismo/irigaray1.pdf.

JESUS, Carolina Maria de. Quarto de despejo: diário de uma favelada. São Paulo: Ática, 2006.

KANT, Immanuel. La Pedagogia. Firenze: La Nuova Italia Editrice, 1963.

LARROSA, Jorge. Experiência e Alteridade em Educação. Revista Reflexão e Ação, Santa Cruz do Sul, v. 19, n. 2, jul./dez. 2011.

MAROH, Julie. O Azul é uma Cor Quente. São Paulo: Arte de Autor, 2016.

ORTEGA, Francisco. Amizade e estética da existência em Foucault. Rio de Janeiro: Graal, 1999. 


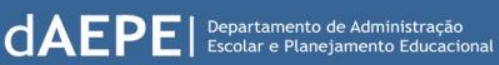

\section{ISSN 2359-82}

SALES JÚNIOR, Ronaldo. Democracia racial: o não-dito racista. Tempo Social, Revista de Sociologia da USP, São Paulo, v. 18, n. 2. p. 229-258, 2006.

SARAMAGO, José. O Conto da Ilha Desconhecida. São Paulo: Companhia das Letras, 1998.

SARTRE, J-P. Entre quatro paredes. Tradução de Guilherme de Almeida. São Paulo: Abril Cultural, 1977. Disponível em: <http://pt.scribd.com/doc/7165285/Jean-Paul-Sartre-EntreQuatro-Paredes.

SCOTT, Joan W. O enigma da igualdade. Estudos Feministas, Florianopólis, v. 13, n. 1, p. 1130, janeiro/abril, 2005.

SILVA, Tomaz Tadeu. O Currículo como Fetiche. Belo Horizonte: Autêntica. 1999.

SIQUEIRA, Cristina (org) Tem Poeta no Morro. Federação das Favelas do Rio de janeiro. Rio Arte. 1987.

STOER, Stephen R.; Magalhãs, António M. Novas cidadanias, reconfiguração do contrato social e educação, 2003. (texto policopiado)

TAN, Shaun. A chegada. São Paulo: Edições SM, 2011.

THOMPSON, Craig. Retalhos. São Paulo: Companhia das Letras, 2009. 